Dossiê: Judaísmo: religião, cultura, nação - Artigo Original ๑。

\title{
Judaísmo enoquita: pureza, impureza e o mito dos vigilantes no Segundo Templo
}

\author{
Enochic Judaism: purity and impurity and the vigilant myth in the Second \\ Temple
}

\author{
Kenner Roger Cazotto Terra * \\ Abdruschin Schaeffer Rocha **
}

\begin{abstract}
Resumo
O artigo se propõe discutir as categorias de "pureza" e "impureza" como instrumentos de estruturação da realidade e construção de identidades, no contexto do judaísmo enoquita, no período do Segundo Templo. Investiga-os, de modo especial, a partir do Mito dos Vigilantes narrado no Livro dos Vigilantes, que compõe a literatura apocalíptica de 1 Enoque (1-16). Tanto a homogeneidade verificada na linhagem garantia a pureza da raça e, consequentemente, o estabelecimento da identidade, quanto a subversão cósmica, resultante de deslocamentos de lugares pré-estabelecidos, estruturava a noção de impureza. 0 artigo apresenta o judaísmo enoquita a partir das pesquisas que tiveram lugar depois da década de 1980. A literatura enoquita é o espaço literário a partir do qual somos lançados à discussão em torno do puro e impuro como categorias de compreensão da realidade na perspectiva desse movimento. $O$ artigo se serve das pesquisas da antropóloga Mary Douglas, para então propor uma análise do Mito dos Vigilantes e suas releituras. $O$ artigo parte do pressuposto de que, em certo sentido, a pluralidade percebida no período do Segundo Tempo instaura possibilidades de pensar a fé na história da tradição judaica. Esse movimento apocalíptico influenciou outros movimentos religiosos, dentre os quais, os cristianismos dos primeiros séculos, razão pela qual algumas experiências religiosas, cujas raízes se encontram na tradição judaico-cristã, podem ser mais bem avaliadas.
\end{abstract}

Palavras-chave: judaísmo; judaísmo enoquita; religião; Segundo Templo; puro-impuro.

\begin{abstract}
The article proposes to discuss the categories of "purity" and "impurity" as tools for structuring reality and constructing identities in the context of Enochic Judaism in the Second Temple period. Investigate them, in a special way, from the Myth of the Watchers narrated in the Book of the Watchers, which composes the apocalyptic literature of 1 Enoch (1-16). Both the homogeneity verified in the lineage guaranteed the purity of the race and, consequently, the establishment of the identity, as well as the cosmic subversion, resulting from displacements of pre-established places, structured the notion of impurity. The article presents Enochic Judaism based on research that took place after the 1980s. Enochic Literature is the literary space from which we are led to discussion around the pure and impure as categories of understanding of reality in the perspective of this movement. The article uses the researches of the anthropologist Mary Douglas, to propose an analysis of the Myth of the Watchers and their readings. The article assumes that, in a sense, the plurality perceived in the Second Temple period establishes possibilities of thinking the faith in the history of the Jewish tradition. This apocalyptic movement has influenced other religious movements, among them, the Early Christianity, which is why some religious experiences, whose roots are in the Judeo-Christian tradition, can be better evaluated.
\end{abstract}

Keywords: judaism; enochic judaism; Second Temple; pure-impure.

Artigo submetido em 13 de fevereiro de 2019 e aprovado em 29 de abril de 2019.

* Doutor em Ciências da Religião pela Universidade Metodista de São Paulo (UMESP). Professor no Programa de Mestrado Profissional da Faculdade Unida de Vitória (FUV). País de origem: Brasil. E-mail: krcroger@gmail.com

** Doutor em Teologia pela PUC-RIO. Professor no Programa de Pós-Graduação em Ciências das Religiões da Faculdade Unida de Vitória. País de origem: Brasil. E-mail: abdo@faculdadeunida.com.br 


\section{Introdução}

A pureza como categoria de análise pode ser instrumento eficaz na compreensão e estruturação da realidade. Para o Judaísmo Antigo a ideia de pureza servia de construção de identidade. Textos tais quais Jubileus (séc. II AEC) e 4QMMT (séc. I AEC) identificam, por exemplo, a linhagem não misturada das gerações como garantia de divisão entre "eles" e o “nós”, puro e impuro (HAYES, 2002, p. 90). A Carta Haláquica, encontrada entre os manuscritos em Qumaran, se auto identifica como "algumas de nossas normas [sobre a lei de D]eus que são part[te dos] preceitos que nós [consideramos e todos eles concernem a [...] a pureza” (4Q394 Frag. 1 col I) (GARCÍA, 2009, p. 130).

Ao lado de outros textos encontrados no Mar Morto, 4QMMT representa parte do Judaísmo do Segundo Templo preocupado com tipos muito específicos de pureza em níveis pessoais e, consequentemente, comunitários. Ainda, as leis de Kashurut, dos alimentos próprios (puros) para o consumo, presentes em Levítico, Deuteronômio, Mishiná e Talmude, são parte da tradição religiosa de grupos judaicos desde as formas mais antigas, mostrando ser o binômio puro/impuro tema importantíssimo da religião e estrutura social judaicas (HAYES, 2002).

Neste trabalho, priorizaremos o período do Segundo Templo, em especial um texto da apocalíptica, o livro de 1 Enoque, o qual representa um movimento judaico conhecido como "judaísmo enoquita”, cuja teodiceia encontra na relação de transgressão cósmica de seres angelicais com mulheres humanas sua primeira e central narrativa. E, a partir dessas imagens enoquitas, especialmente no Livro dos Vigilantes, no qual está o Mito dos Vigilantes (1 En 1-16) e suas recepções, encontramos o desenvolvimento do conceito de impureza por intermédio dos deslocamentos de lugares estabelecidos; ou seja, a subversão cósmica como estabelecimento do impuro. A importância dessa narrativa é percebida por suas releituras e cópias em diversos outros documentos das tradições judaicas que, por sua vez, precisam ser tratadas no plural por aceitarmos a complexidade desse fenômeno cultural no Segundo Templo. 
O artigo, inicialmente, apresentará o movimento enoquita à luz de pesquisas pós-década de 80. Na sequência, apresentar-se-á a literatura enoquita e suas mais importantes partes, o que nos lançará na discussão em torno do puro e impuro como categoria de compreensão da realidade desse movimento. Com auxílio das pesquisas de Mary Douglas, analisaremos o Mito dos Vigilantes e suas releituras como exemplo da perspectiva comum no Judaísmo do Segundo Tempo: a impureza ligada à desordem e transgressão de fronteiras.

\section{0 judaísmo enoquita no Segundo Templo}

Antes de qualquer discussão relacionada a movimentos religiosos judaicos, faz-se necessário perguntar-se pelo conceito de Ioudaismós (judaísmo). Nos últimos anos, os termos "Judaísmo", “Judeu” ou “Judaico" tornaram-se matéria de acirradas discussões: referem-se a questões étnicas ou religiosas? Em que momento pode-se usá-los na história? Qual a relação com “Israel”, “israelita” e outros? (GRABBE, 2000, p. 5). Assim como os gregos, no que diz respeita à compreensão de si e da própria identidade, os judeus se identificavam pelo "sangue comum", "língua comum", “comum modo de adoração a Deus" e "práticas de vida comuns" e, mais do que na compreensão grega, a identificação étnica (COHEN, 1999, p. 133). Contudo, Shaye J. D. Cohen, por exemplo, defende que o termo “judeu” relacionado a práticas públicas, mudança e aceitação de modo de vida, em horizontes religioso e cultural, melhor se enquadra ao período posterior aos hasmoneus, já que antes disso o termo "judeu” significava simplesmente "o habitante da Judéia”.

Mesmo que "judaico" sempre contivesse seu significado étnico, o modo comum de adoração e o modo de vida comum tornaram-se muito mais importantes na nova definição de judeu/judaico. Assim como um bárbaro se tornava um helênico ao falar grego e adotar o modo de vida grego, um gentio poderia se tornar um judeu através da adoração ao Deus de Jerusalém (isto é, acreditando firmemente em Deus) e/ou adotando o modo de vida judaico (ou seja, observando as leis ancestrais judaicas). Foi essa redefinição hasmoneia do judaísmo que 
permitiu Josephus no final do primeiro século d.C. afirmar que a constituição estabelecida por Moisés não era apenas de gene - uma nação, um "nascimento" mas, também, "escolha por uma maneira de vida". Essa redefinição hasmoneia levou o autor judeu do primeiro século da E.C à radical ideia de que Jewishness não é étnico, mas totalmente questão de crença: afinal, não é no exterior que se faz um verdadeiro Ioudaios, ao contrário, ele se verifica interiormente (COHEN, 1999, p. 133-134.).

Por questões práticas e para fins de inclusão, sob a nomenclatura "Judaísmo" inserem-se indivíduos e comunidades rotulados nas fontes com esse epíteto (Yehudi, Yehudim/Iouda, Ioudaios/ Ioudaioi, Judeia, Judeus, Judaico), comunidades e indivíduos que adoram Yhwh (ou o Deus dos Judeus) e observadores das práticas associadas apenas aos judeus (GRABBE, 2000, p. 5).

Importante para nossa discussão, por ser tradicional nas pesquisas, usado para identificar o período quando a identidade "judaica” se formaliza, é a expressão "Segundo Templo". Trata-se de um período marcado por diversos movimentos. Segundo Templo é termo técnico, às vezes tratado como sinônimo de Judaísmo Antigo (Early Judaism), usado para indicar o período entre o pós-exílio (séc. VI A.E.C) até a segunda metade do Sec. I E.C (por ocasião da destruição do tempo em 70 E.C). O Judaísmo do Segundo Templo desenvolveu crenças e práticas em diálogo com as culturas persa, grega e romana. O Misticismo Judaico, a Apocalíptica Judaica, grande parte da TaNak e literatura de Qumran pertencem a esse complexo contexto histórico-cultural (GRABBE, 2000, p. 6.). A indiscutível diversidade religiosa desse período levou os especialistas a criticarem compreensões monolíticas. Por isso, a defesa de um “Judaísmo comum” (Common Judaism) - como quer E. P. Sanders ${ }^{1}$ - no período do Segundo Templo, centrado no sacerdócio e no templo, o qual partilhava em suas variações um núcleo ortodoxo comum, desde há muito é alvo de críticas e descrédito nas atuais pesquisas, afinal,

\footnotetext{
${ }^{1}$ Sanders (1992) afirma que sua pesquisa "é o esforço para descrever o judaísmo comum, o dos sacerdotes comuns e as pessoas comuns", o que significaria haver um tipo ideal de judaísmo estabelecido a partir de práticas e crenças comuns no período do Segundo Templo, em especial no séc. I d.C. (ver especialmente o cap. 5: "Common Judaism and the Temple").
} 
escamoteia anacronicamente a multiplicidade de movimentos, por vezes contraditórios, no Judaísmo Antigo². Por essa razão, os pesquisadores entenderam ser mais legítimo usar "judaísmos", no plural, pois abarcaria a complexidade e multiplicidade de movimentos e grupos, os quais, mesmo perpassados por temas ou imaginários comuns, devem ser analisados em suas particularidades e diferenças ${ }^{3}$. Charlesworth, por sua vez, introduzindo sua monumental coletânea, ao tratar da importância da literatura pseudepígrafa, faz o equilíbrio entre unidade e pluralidade do judaísmo do Segundo Templo. Ele admite que a variedade, até contraditória, das ideias populares em muitos setores do judaísmo pós-exílio mostra que tal fenômeno "não era estruturado monoliticamente, nem dividido a partir de um centro ortodoxo todo-poderoso" (CHARLESWORTH, 1985, p. XXIX). No entanto, o pesquisador de Princeton acrescenta que é insensato tornar quase não identificável a identidade exagerando na diversidade, porque "no primeiro século, o judaísmo não era uniformemente normativo nem caoticamente diverso"4. A interpretação de Charlesworth permite mais sensatez e equilíbrio na pesquisa, mas não esconde a pluralidade do judaísmo no Segundo Templo - no máximo coloca limites.

Entre os movimentos judaicos desse período, além dos fariseus, saduceus ou essênios (GRABBE, 2000), as pesquisas desenvolveram a hipótese do judaísmo enoquita, cuja existência é intuída a partir dos textos da tradição enoquita (1 Enoque [Enoque Etíope], 2 Enoque [Enoque Eslavo], Jubileus, alguns textos de Qumran e outras obras relacionadas a essa tradição). Desde 1979, num artigo da revista Henoch, Paolo Sacchi apresentou 1 Enoque não somente como um protótipo do gênero apocalíptico, mas, também, de uma distinta variante do judaísmo (TERRA, 2010). G. Nickelsburg (NICKELSBURG, 2001.) confirma a existência desse movimento e relativiza o papel da lei mosaica entre os enoquitas. A partir

\footnotetext{
2 Martin Hengel e Roland Deines usam o termo "judaísmo complexo", uma terceira via entre Judaísmo comum e diverso (HENGEL, 1995, p. 1-41).

${ }^{3}$ Para discussões a respeito da pluralidade de judaísmos e cristianismos, ver Neusner; Green; Frerichs (1987); Neusner (1998); Neusner (1994); Chevitarese (2003). Para uma discussão sobre identidade judaica a partir das percepções da pluralidade de judaísmos, ver Goodman (2007); Cohen (1999); Nogueira; Funari; Collins (2010).

4 "[...] in the first century Judaism was neither uniformly normative nor chaotically diverse" (CHARLESWORTH, 1985, p. XXIX).
} 
desses trabalhos, nos últimos anos, figuras importantes como Boccaccini defende a existência desse movimento e avança, relacionando-o com o essenismo (TERRA, 2010).

Seguindo essa mesma discussão, seria possível afirmar que "um movimento ou comunidade pode também ser apocalíptica se esta for formada, em certo grau, por uma específica tradição apocalíptica” (COLLINS, 1997, p. 37). Tal perspectiva permite afirmar que há uma “tradição apocalíptica enoquita”, cuja base seria o livro de 1 Enoque. O enoquismo, ainda que com diferentes composições forma um mesmo movimento, ou está alicerçado em uma mesma tradição; suas diferenças servem para ampliar, na verdade, a visão de mundo de uma obra para a outra (TERRA, 2010).

Esse grupo acreditava possuir a sabedoria divina contida nos textos de 1 Enoque, a qual tornava seus membros uma comunidade escatológica de escolhidos que esperavam o julgamento e a consumação do fim dos tempos. Na verdade, não podemos saber como se chamavam ou se autodenominavam, mas, certamente tinham Enoque como figura central (TERRA, 2010).

Como defende Boccaccini, e corrobora Terra, esses textos de Enoque foram escritos por membros do sacerdócio de Jerusalém, mas um grupo anti-zadoquita. Uma espécie de movimento sacerdotal dissidente, ativo em Israel no fim do período persa e início do helênico (séc. IV) (BOCCACCINI, 1998, p. 78; TERRA, 2010, p.54). Boccaccini deixa claro, porém, que o enoquismo era um grupo de oposição entre a elite do templo e não um simples grupo de separatistas. No entanto, o centro do judaísmo enoquita não era a Torá nem o templo. Os dois grupos (zadoquitas e enoquitas) interpretavam Ezequiel de formas diferentes e tinham ideias completamente contrastantes sobre a origem do mal. Até cerca de 200 A.E.C, enoquismo e zadoquismo eram duas linhas de pensamento distintas e paralelas no judaísmo (TERRA, 2010, p. 53-54). 
Reed, tratando da questão do conteúdo de 1 Enoque, explica que "a brevidade do conteúdo bíblico fica acentuada, ao contrastarmos com a riqueza de tradições sobre Enoque no Judaísmo e Cristianismo" (REED, 2005, p. 1). Isso porque a Bíblia Hebraica é muito tímida na descrição de Enoque (Gn 5,21-24; $1 \mathrm{Cr}$ 1,3). A partir do Judaísmo do Segundo Templo, grupos judaicos produziram uma enorme quantidade de literatura (TERRA, 2010). Por sua vez, o Livro dos Vigilantes, a primeira parte da obra enoquita, é considerada um dos primeiros livros da apocalíptica judaica. Na década de 70, J. T. Milik editou os fragmentos aramaicos encontrados em Qumran (MILIK, 1970). Segundo este autor, o livro Astronômico é anterior ao Livro dos Vigilantes5. Contudo, "este tem provado ter mais utilidade na iluminação da emergência e desenvolvimento da literatura apocalíptica, especialmente concernente à origem do mal” (REED, 2005, p. 53).

\section{A obra central do judaísmo enoquita: 1 Enoque}

A divisão dos livros de 1 Enoque é a seguinte: Livros dos Vigilantes (6-36); Parábolas de Enoque (37-71); Livro Astronômico (72-82); Livros dos Sonhos com o apocalipse dos Animais - (83-90); Epístola de Enoque (91-105), dentro do qual ainda encontramos o Apocalipse das Semanas (93, 1-10; 91, 11-17). Em Qumran foram achadas, em aramaico, partes de todos os livros de 1 Enoque $^{6}$ - à exceção do livro das Parábolas. Do Livro Astronômico, por exemplo, foram encontradas quatro copias em lugares diferentes. Um fato intrigante para os pesquisadores é a presença de onze cópias do "Livro dos Gigantes" (1Q23; 2Q26; 4Q203; 4Q530-3; 6Q8) 7 (TERRA, 2010).

No Livro dos Vigilantes verifica-se a origem do mal e suas relações com a cultura. Narra-se a subversão dos anjos Vigilantes às fronteiras cósmicas para coabitarem com mulheres e as consequências desastrosas dessa união. Além disso,

\footnotetext{
${ }^{5}$ Boccaccini propõe a seguite ordem: Livro dos Vigilantes (1-36), Livro Astronômico (72-82), Livro dos Sonhos (83-90), Epístola de Enoque (91-105), Parábola de Enoque (37-71). (BOCCACCINI, 1998. p. 12).

${ }^{6}$ Livro Astronômico (4Q208-11); Livro dos Vigilantes (4Q201, 202); combinação do Livro dos Sonhos e Livro dos Vigilantes (4Q201,202). 4Q204 tem fragmentos do Livro dos Vigilantes, Livro dos Sonhos, Epístola de Enoque e o Livro de Noé (1 Enoque 104-107). Ainda temos outros fragmentos do Livro dos Sonhos (4Q207) e da Epístola de Enoque (4Q212).

${ }^{7}$ Para uma exposição detalhada do Livro dos Gigantes, ver García Martínez (1994, p. 97-115).
} 
nesse livro se encontram as viagens de Enoque ao redor do mundo (VANDERKAM, 1995). No livro Parábolas de Enoque, um texto mais recente, trabalha-se a ideia de condenação e salvação. Nele há uma estruturação cósmica e dos seres celestes responsáveis por setores da ordem celestial e dos astros. Há a citação do Filho do Homem e a destruição realizada pelo Messias. Esse bloco revela imagens de condenação de reinos e as formas de tortura preparadas pelos anjos. A obra termina com a apresentação dos monstros caóticos criados por Deus, o castigo dos anjos caídos (Vigilantes) e a exaltação de Enoque como Filho do Homem.

O Livro Astronômico, por sua vez, apresenta as leis dos astros que foram explicadas pelo Arcanjo Uriel. Fala-se do calendário solar e sobre o ano solar de 364 dias. Em linguagem escatológica, mostra-se a desordem cósmica no fim dos dias. O Livro dos Sonhos é a exposição de duas visões a respeito do futuro do mundo e de Israel em uma perspectiva pré-diluviana. Com linguagem alegórica, descreve o dilúvio e história do mundo de Adão até o reino messiânico. No Livro dos Sonhos, "os bois simbolizam os patriarcas; ovelhas, os israelitas fiéis; as bestas e aves de rapina, os opressores pagãos de Israel; uma grande ovelha com chifres, um líder judeu nascente; um touro branco com grandes chifres, o Messias" (CHARLESWORTH, 1983, p. 5.). Nessa obra está o Apocalipse dos Animais (1 En 85-90), no qual se mostra a história dividida em três eras que culminam no julgamento final, quando a Nova Jerusalém é construída, os gentios prestam homenagens aos judeus, a diáspora retorna e os mortos são ressuscitados. Nesse livro os Vigilantes são tratados como estrelas caídas; os anjos caídos se tornam bois e têm relações com as vacas e novilhas (as mulheres); isso instaura o caos com o nascimento dos "gigantes" (camelos, elefantes etc.).

A Epístola de Enoque é uma parênese. No livro, Enoque exorta os filhos e os justos em geral a seguirem o caminho da virtude. O texto fala da reparação futura dos sofrimentos dos justos. Aqui está localizado o Apocalipse das Semanas (91,1217; 93,1-10), que é um apocalipse de tipo histórico, por meio do qual se conta a história do mundo, indicando fatos marcantes de cada semana; as últimas três mostram o juízo final, o reino messiânico, conversão dos gentios e o novo céu. No 
fim do livro há um apêndice de obras fragmentadas (que supostamente seriam do Apocalipse de Noé), uma exortação sobre o castigo dos pecadores e a salvação dos justos (105-108).

Essa vasta literatura ligada à figura de Enoque tem como mito fundante o Mito dos Vigilantes (1 Enoque 6-11), que é a primeira parte do Livro dos Vigilantes. Esta parte da obra enoquita tem características marcantes de uma teodiceia. No contexto dessa temática aparecem os ensinamentos celestes ilícitos e o tema da impureza/pureza. Em suas apropriações e recepções ocorrem novas imagens acumuladas e preservadas em vários textos. Os textos enoquitas testemunham que o mal e impureza no mundo são resultados de uma rebelião angelical. Esse tema acabou sendo desenvolvido em testemunhas textuais, ganhando novas formas (VANDERKAM, 1995).

1 Enoque, com os achados de Qumran, recebeu datação pré-macabaica (NICKELSBURG, 1977, p. 397-398), e por sua linguagem e imagens (que perpassam longamente a tradição apocalíptica) é percebido como primeiro apocalipse, em especial o Livro dos Vigilantes e o Livro Astronômico. O primeiro tornou-se grande canalizador dos símbolos e expressões religiosas das culturas babilônicas, Persas e helênicas. Entre tantos assuntos do judaísmo enoquita, o tema impureza/pureza tornou-se instrumento de estruturação da realidade e construção de identidade no Segundo Templo.

\section{Puro e impuro no mundo antigo e judaísmo enoquita}

A ideia de impureza está presente no mundo imaginário da narrativa dos Vigilantes em dois pontos: 1) Anjos que deixam seu posto cósmico, e 2) pela prática alimentícia dos gigantes. Em relação à primeira, na literatura enoquita e suas recepções aparecem constantemente a imagem da movimentação de seres que estavam em linhas imaginárias estabelecidas de céu e terra, em uma ordem cósmica. De acordo com o relato dos capítulos 6-11, um grupo de seres angelicais, nomeados como Vigilantes, foi atraído pela beleza das filhas dos homens 
(mulheres) e conspirou entre si sob a liderança de Semiaza, com o propósito de possuírem-nas (TERRA, 2010, p. 41).

Quando os filhos dos homens se multiplicaram, naqueles dias, nasceramlhes filhas bonitas e graciosas. E os vigilantes, filhos do céu, ao verem-nas, as desejaram e disseram entre si: "Venham, escolhamos para serem nossas esposas as filhas dos homens, e tenhamos filhos!" Disse-lhes então o seu chefe Semiaza: "Eu receio que vós não queirais realizar isso, deixando-me no dever de pagar sozinho o castigo de um grande pecado". Eles responderam-lhe e disseram, "Nós todos estamos dispostos a fazer um juramento, comprometendo-nos a uma maldição comum, mas não abrir mão do plano, e assim executá-lo". Então eles juraram conjuntamente, obrigando-se a maldições que a todos atingiram. Eram ao todo duzentos os que, nos dias de Jared, haviam descido sobre o cume do monte Hermon. Chamaram-no Hermon porque sobre ele juraram e se comprometeram a maldições comuns. (1 Enoque 6,1-5).

O bloco 85-90 de 1 Enoque é conhecido como Apocalipse dos Animais. Usando linguagem alegórica, os personagens dessas narrativas são representados, em sua maioria, por animais (TERRA, 2010). Somente os anjos são tratados como estrelas, mas que se tornam, logo depois de sua queda, em bois (touros). Sua queda está relacionada ao estabelecimento do caos e desastres humanos. No capítulo 86, Enoque tem uma visão, na qual uma estrela cai do céu. Esta se levanta e pasta entre os bois. Depois dela, outras estrelas caem também e fazem a mesma coisa. Essa queda produz conflitos, por tomarem as mulheres, que no texto são as vacas, o que gera os elefantes, camelos e asnos. Como uma releitura do Mito dos Vigilantes, esses seres começaram a comer tudo, uma grande carnificina.

Essa ordem cósmica, que é violada, está exposta especialmente no Livro Astronômico (1 En 72-82). Nessa obra, Enoque é levado através do cosmo e conhece suas leis de funcionamento: “com repetição monótona e cálculos de predições ad infinitum, a abordagem demonstra a uniformidade e ordem da criação de Deus segundo é evidenciada nos movimentos dos luminares e sopro dos ventos” (NICKELSBURG, 1981, p. 101).

Malaki'el, Hela'melek, Milay'ul, 'Adanar'ul, Tyasus-'el, 'Elum'el - os três que seguem os líderes dessa ordem, assim como os quatros, os quais seguem à frente dos três líderes das ordens, os quais seguem depois daqueles líderes das estações que dividem as quatro temporadas do ano. No início, Malkiyal, o qual é chamado de Tamayen - e o sol - sobem e descem [...]. (82, 14-15). 
Segundo este texto, cada anjo está responsável por um lugar fixo, onde deve cumprir uma função na organização cósmica, através da qual as estações são desenvolvidas. Os anjos estão na organização das estrelas e quase se confundem com elas. Com a queda das estrelas, segundo essa imagem, gera-se uma desestabilização da organização, porque esses lugares dão sistematização ao mundo. Essa transgressão de fronteiras está ligada à impureza.

De acordo com Mary Douglas, a pureza é um agente estruturante da sociedade (DOUGLAS, 1966). Esse conceito é mais bem compreendido em termos de sua oposição binária: "sujeira”. Por isso a antropóloga inglesa inicia a sua argumentação partindo da ideia de que a sujeira é composta de duas premissas: (1) cuidado com a higiene e (2) respeito a convenções. É exatamente nesse segundo ponto que são desenvolvidas as suas hipóteses de leitura e compreensão das regras de puro/impuro nas culturas estudadas (TERRA, 2010, p. 41). Ela afirma que sujeira é essencialmente desordem.

Não há sujeira absoluta: ela existe aos olhos de quem a vê. Se evitamos a sujeira não é por covardia, medo, nem receio ou terror divino. Tampouco nossas idéias (sic) sobre doença explicam a gama de nossos comportamentos no limpar ou evitar a sujeira. A sujeira ofende a ordem. Eliminá-la não é um movimento negativo, mas esforço positivo para organizar o ambiente. (DOUGLAS, 1966, p. 12).

Citando Mary Douglas, Kenner Terra descreve a sujeita, contrário da pureza, em duas condições: (a) um conjunto de relações ordenadas e (b) uma contravenção dessa ordem, chegando a afirmar que "onde há sujeira, há sistema” (TERRA, 2010, p. 41; DOUGLAS, 1966, p. 50).

A sujeira seria um subproduto de uma ordenação e classificação sistemática de coisas, na medida em que a ordem implique rejeitar elementos inapropriados. Esta ideia de sujeira leva-nos diretamente ao campo do simbolismo e promete uma ligação com sistemas mais obviamente simbólicos de pureza. (DOUGLAS, 1966, p. 50).

Os lugares estabelecidos criam uma ordem. Assim, o impuro seria exatamente as coisas que estivessem fora do lugar. O impuro, nessa perspectiva, poderia ser a transgressão das fronteiras, a mudança simbólica dos lugares estabelecidos. 
O sistema cultural é a representação da pureza, pois está em ordem estabelecida cujo conteúdo serve como organização de um grupo. Assim, a ideia de pureza é uma maneira abstrata de lidar com os valores, mapas e estruturas de um dado grupo (TERRA, 2010). Há um lugar marcado e estruturado para as coisas: tudo tem seu lugar (NEYREY, 1986, p. 92). Por isso, diria Mary Douglas, santidade e pureza se interpenetram e revela-se como permanência e preservação dos lugares/classes de pertencimento, porque qualquer mudança tocaria essa condição (DOUGLAS, 1966). Assim, mistura e cruzamento de fronteiras significaria respectivamente desordem e impureza.

$\mathrm{Na}$ tradição dos vigilantes, seres celestiais abandonam o céu e vão para Terra, destruindo a ordem estabelecida por Deus e misturando carne e espírito. Como diz 1 En 9,8: "Têm ido até as filhas dos homens [...] e com elas cometido impureza".

[...] Vocês, santos espirituais, viviam na vida eterna, tornaram-se impuros com o sangue das mulheres, com sangue mortal têm gerado [os gigantes], sangue humano haveis desejado, produzindo carne e sangue, como fazem os que são mortais e perecedores. (1 En 15,4).

No mesmo capítulo 15 afirma-se que a razão do mal, ou seja, o seu lugar é no céu: "porque os seres espirituais têm o seu lugar no céu" (15,7). Ou seja, o mal (a impureza) se estabeleceu porque houve a mistura carne-espírito. Em Testamento de Naftali, como releitura do Mito dos Vigilantes, temos a crítica aos Vigilantes que "subverteram a ordem da natureza" (Test. de Naf. 3,4-5).

Por trás dessa relação híbrida está a desestabilização de um sistema que o próprio texto deixa visível. O quadro abaixo, desenvolvido por Terra, mostra esse esquema:

\section{Quadro 1}

\begin{tabular}{|l|l|}
\hline Mulheres & Vigilantes \\
\hline Espécie: Sangue/carne/mortal & Espécie: espiritual \\
\hline Fronteira: Mundo humano & Fronteira: celestial \\
\hline Relação: humano (mortais, perecedores) & Relação: eternidade \\
\hline
\end{tabular}

Fonte: (TERRA, 2010, p. 44) 
Há nitidamente a transgressão das fronteiras carne-espírito, humanoceleste, mortal-eternidade, como se houvesse uma linha demarcatória organizadora. Há uma ordem cósmica estabelecida, a qual é transgredida e se estabelece o caos. No próprio livro de 1 Enoque, especialmente no Livro Astronômico, encontra-se o mundo dos seres e sua organização.

Na lista dos seres que descem do céu há um elenco de seres que possuem posições, hierarquias e funções na organização cósmica (1 En 6,5-8). Ao descerem, eles desorganizam o cosmos organizado por Deus. Tais desorganizadores do cosmos geram seres híbridos: os gigantes. Estes violam algumas leis e ao mito é amalgamada a transgressão de leis sociorreligiosas e violência. Carne sem discriminação: "e eles começaram a atacar os pássaros, os animais selvagens, os répteis e os peixes" (7,1-6); bebem sangue: "rasgaram com os dentes as suas carnes e beberam o seu sangue" $(7,6)$; antropofagia: "os gigantes começaram a matar os homens e a devorá-los” (7,6); “cada um devorou seu próprio parceiro” (TERRA, 2010, p. 45).

\section{Como afirma Terra:}

As imagens e transgressões presentes em 1 Enoque revelam ações que subvertem as leis de pureza e segundo o código de Levítico, os gigantes acabaram infringindo regras de pureza relacionadas à alimentação. No texto, os gigantes comem tudo indiscriminadamente: animais selvagens, répteis e peixes. Os gigantes bebem o sangue de todos eles, o que os torna impuros segundo as leis do Levítico. A punição, em Levítico, seria a separação da comunidade, enquanto no Livro dos Vigilantes é a separação da vida física entre os homens e prisão no abismo [...]. Em Lv 19,26 acontece algo interessante: o comer sangue está junto à proibição de práticas de adivinhação e encantamentos. No Mito dos Vigilantes, ligado à sua (re)apropriação, essas duas proibições são violadas. (TERRA, 2010, p. 45-46).

A prática dos gigantes de comer sangue se junta aos ensinamentos de magia e feitiço dos Vigilantes, seus pais (1 En 8,2). A questão da impureza é amalgamada à imagem dos anjos que descem. Descer, torna a terra caótica e violar as ordens celestiais e sociais. O quadro de terror e violência vincula-se ao imaginário dos ensinos impróprios. 
No Mito dos Vigilantes há pelo menos três sumários em que são apresentadas as ações dos anjos consideradas perniciosas (7,1-6; 8,1-4 e 9,6-10). A esses se agrupam o tema da condição de impureza/caos dos Vigilantes e a violência posterior. O primeiro da lista é 7,1-7:

E tomaram mulheres; cada um escolheu a sua para conviver e unir-se a ela, ensinando-as magia, palavras de maldição, cultivos de raízes e ervas. Engravidaram as mulheres e geraram gigantes, que devoraram todos os produtos dos homens, até que foi impossível alimentá-los. Então os gigantes se voltaram para contra eles (homens) e todos os animais, devorando-os e bebendo seu sangue. Então a terra se queixou contra eles. (1 En 7,1-6).

O outro texto completa o quadro, cuja imagem mostra que os anjos ensinaram algumas práticas às mulheres, diferentemente dos outros sumários que expõem um ensinamento a todos os homens:

Azazel ensinou aos homens a arte de fabricar espadas, facas, escudos, armadura peitoral, e técnicas para os metais, braceletes e adornos; como pintar os olhos e embelezar as sobrancelhas. Entre as pedras preciosas, escolher as mais caras e preciosas, e a metalurgia. Houve grande impiedade e muita fornicação, e corromperam os bons costumes [...]. Semiaza ensinou encantamentos e as porções de feitiço. Herman ensinou feitiçaria e dissipação de encantamentos, mágica e outras técnicas. Baraqel ensinou a leitura dos sinais dos relâmpagos. Kokabel ensinou a leitura dos sinais das estrelas. Ziqel ensinou a leitura dos sinais das estrelas cadentes. Arteqof ensinou os sinais da terra. Shamsiel ensinou os sinais do sol. Sahriel ensinou os sinais da lua. E todos eles começaram a revelar os mistérios às suas esposas e seus filhos e os homens pereceram, e o lamento chegou ao céu. (1 En 8,1-4).

$\mathrm{Na}$ tradição enoquita, Azazel ensina os mistérios às esposas e filhos, ensinamentos impróprios. Ele encabeça a lista e é o culpado pela origem das armas de guerra e da luxúria feminina. Desta forma, a transgressão de fronteiras gera ensinos impróprios e mistura não só de céu-terra, mas de sabedoria celestehumana.

Outro conjunto de textos importantes para esse tema em Enoque são os sumários. A ideia de que deveriam permanecer em seu devido lugar está presente, por exemplo, no sumário em 1 En 9,6-10, "no qual se diz que Azazel ensinou os eternos mistérios do céu e os fez conhecidos aos homens (v. 6), enquanto Semiaza ensinou os conjuros (v.7)” (TERRA, 2010, p. 47). 
No Livro das Parábolas (1 En 69,1-12), mais uma vez encontramos a presença de seres que deixam o céu, transgredindo seus lugares estabelecidos, e levam para espaços não autorizados ensinos celestiais:

O terceiro foi chamado Gader'el; este é aquele que mostrou aos filhos do povo todos os golpes da morte, o que enganou a Eva, que mostrou aos filhos do povo (como fazer) os instrumentos da morte: o escudo, o peitoral e a espada para a guerra e todos (os outros) instrumentos de morte para os filhos do povo. Através de seu arbítrio a morte está contra as pessoas que habitam na terra daquele dia para todo o sempre. O quarto é chamado Pinem'el, esse demonstrou aos filhos do povo o amargo e o doce e reveloulhes todos os segredos de sua sabedoria. Além disso, ele ensinou as pessoas a penetrarem o segredo da escrita e o uso de tinta e papel. Por conta disso, há muitos que erraram desde a eternidade até a eternidade, até o dia de hoje [...]. Pois de fato, os seres humanos foram criados para serem como anjos, permanentemente com vida pura e justa [...]. (1 En 69, 8-12).

Como se percebe no texto, a cultura da guerra e da escrita são saberes não terrenos, ensinados e motivados pelos seres celestes, responsável por estabelecer a violência e o erro no mundo. Dessa forma, o deslocamento dos lugares estabelecidos possibilita saberes não autorizados, o que significa a instauração da morte e impureza, porque, como diz o texto, "os seres humanos foram criados para serem como anjos, permanentemente com vida pura e justa” (v. 12).

Da mesma maneira, na tradição enoquita, tanto as relações entre os Vigilantes quanto os Gigantes representam a impureza. Estes, segundo a narrativa, são o protótipo da impureza, primeiramente por conta de sua alimentação. Segundo o texto, eles comem de tudo, inclusive os próprios seres humanos (1 En 7,1-6). Eles são o resultado direto da ação de transgressão de fronteiras, são seres híbridos. No cap. 15 de 1 Enoque somos informados, inclusive, que os espíritos que saem dos corpos desses Gigantes, como marca identitária mais profunda, são tratados como espíritos imundos. Por saírem de corpos híbridos são essencialmente maus. O texto, nesse capítulo, deixa claro que o lugar dos Vigilantes era o céu, por isso não tinham esposas $(15,7)$. E mais, essa união Céu-Terra produziu os seres híbridos, os gigantes: os “que nascem da união dos espíritos e da 
carne serão chamados maus espíritos sobre a terra, porque sua morada estará sobre a Terra e dentro da terra. Espíritos malignos saíram deles” (15, 8-9).

O Mito dos Vigilantes e suas traduções no judaísmo do Segundo Templo representam o mundo ao seu redor como lugar de transgressões de fronteiras e impurezas. Como o templo terrestre está - segundo esse movimento - em total impiedade, resta-lhes somente a destruição final e sua reformulação cósmica como caminho de implantação da pureza. Esse tipo de judaísmo, entre tantos outros, serviu de material simbólico e contexto discursivo representado nos manuscritos do Mar Morto e nos cristianismos das origens.

\section{Conclusão}

O período do Segundo Templo, marcadamente plural, guardadas as reservas indicadas por Charlesworth, representa as múltiplas possibilidades de se pensar a fé na história da tradição judaica. Mesmo que algumas alas mais conservadoras não aceitem, o judaísmo não tem fronteiras rígidas, pelo menos não no Mundo Antigo. As pesquisas avançaram e demonstraram a importância das outras culturas para a formação de sua identidade e como as experiências locais, desde a diáspora, formataram a complexidade das identidades religiosas dos judaísmos antigos. Entre estes, desde o início do século passado, identificou-se o judaísmo enoquita, até então desconhecido pelos estudiosos do mundo judaico.

Como movimento importante para os judaísmos do período pós-exílico em diante, o judaísmo enoquita e seu imaginário permeado pelos conceitos de puro e impuro, condensados às imagens de violência e transgressão, representam uma proposta de compreensão da realidade e estruturação de mundo. A realidade segundo essa perspectiva judaica é habitada por seres celestiais em conflito, tomados de desejos eróticos, os quais transformam a criação em lugar para estabelecimento de desordem. Nesse conjunto de textos e crenças, a corporeidade e suas transgressões são previstas como intercambiáveis. Ao lado disso e como lugar 
de compreensão dessa relação, há o conceito de fronteiras cosmicamente estabelecidas. Por sua vez, somente a perspectiva do fim dos tempos, de Novo Céu e Nova Terra, pode ser a única resposta possível, o que impregnará de fatalismo a compreensão da história.

As obras, tradições e imaginários religiosos que são identificados nesse grandioso movimento apocalíptico influenciaram outros tantos movimentos religiosos antigos e modernos, entre eles os cristianismos dos primeiros séculos. Jesus e seus primeiros seguidores, de João a Paulo, eram judeus inseridos no contexto do Segundo Templo. Por isso, o judaísmo enoquita não deveria ser preocupação somente para quem deseja particularmente compreender grupos do Mundo Antigo, já que ajuda na avaliação das experiências religiosas atuais cujas raízes estão na tradição judaico-cristã, nas quais encontramos uma estruturação de mundo perpassada pelo binarismo puro/impuro ou crenças em espíritos malignos impuros.

\section{REFERÊNCIAS}

BOCCACCINI, Gabriele. Beyond the essene hypothesis: the parting of the ways between Qumran and Enochic Judaism. Grand Rapid: William B. Eerdmans, 1998.

BOCCACCINI, Gabriele. Introduction: from the Enoch Literature to Enochic Judaism. In: BOCCACCINI, Gabriele. Enoch and Qumran origins: new light on a forgotten connection. Grand Rapids: William B. Eerdmans Publishing Company, 2005.

CHARLESWORTH, J. H. Introduction for the general reader. In: CHARLESWORTH, J. H (Ed.). The Old Testament pseudepigrapha - Vol. 2. New York: Doubleday, 1985.

CHARLESWORTH, James H. The Old Testament pseudepigrapha - Vol. 1. New York: Doubleday, 1983.

CHEVITARESE, André Leonardo; CORNELLI, Gabriele. Judaísmo, Cristianismo, Helenismo: ensaios sobre interações culturais no Mediterrâneo Antigo. Itu: Ottoni Editora, 2003.

COHEN, S. J. D. The beginnings of jewishness: boundaries, varieties, uncertainties. Berkeley: University of California Press, 1999. 
COLLINS, AdelaYarbro. The combat myth in the book of revelation. Eugene: Wipf and Stock Publishers, 2001.

COLLINS, J. J. Seers, sibyls and sages in Hellenistic-Roman Judaism. Leiden: Brill, 1997.

DOUGLAS, Mary. Pureza e perigo. São Paulo: Perspectiva, 1966.

GARCÍA MARTÍNES, Florentino. Qumran and apocalyptic: studies on the aramaic texts from Qumran. Leiden: E.J. Brill, 1994.

GARCÍA MARTÍNEZ, Florentino. Qumranica minora I: Qumran origins and apocalypticism. Leiden: Brill, 2007.

GARCÍA MARTÍNEZ, Florentino. Textos de Qumrán. Madrid: Editora Trotta, 2009.

GOODMAN, Martin. Rome and Jerusalem: the clash of ancient civilizations. London: Penguin Books, 2007.

GRABBE, Lester L. Judaic religion in the second temple period belief and practice from the exile to Yavneh. London: Routledge, 2000.

HAYES Christine E. Gentile Impurities and Jewish identities: intermarriage and conversion from the Bible to the Talmud. New York: Oxford University Press, 2002.

HENGEL, M.; DEINES, Roland. E. P. Sanders' common Judaism, Jesus, and the pharisees: review article of Jewish law from law from Jesus to the Mishnah and Judaism: practice and belief and belief by E. P. Sanders. In: The Journal of Theological Studies, Oxford, v. 46, n. 1, p. 1-41, abr. 1995.

MILIK, J. T. The books of Enoch: aramaic fragments of Qumran cave 4. Oxford: Clarendon Press, 1970.

NEUSNER, Jacob. The four stages of rabbinic Judaism. London: Routledge, 1998.

NEUSNER, Jacob. The Judaism the rabbis take for granted. Atlanta: Scholars, 1994.

NEUSNER, Jacob; GREEN, William Scott; FRERICHS, Ernest S. Judaisms and their messiahs at the turn of the Christian era. Cambridge: Cambridge University Press, 1987.

NEYREY, Jerome H. The idea of purity in Mark's Gospel. Semeia, Atlanta, n. 35, p. 91$127,1986$.

NICKELSBURG, George W. E. Apocalyptic and myth in 1 Enoch 6-11. Journal of Biblical Literature, Atlanta, v. 96, n. 3, p. 397-398, 1977.

NICKELSBURG, George W. E. 1 Enoch: a commentary on the book of 1 Enoch, chapters 1-36; 81-108. Minneapolis: Fortress, 2001. 
NICKELSBURG, George W. E. Jewish literature between the Bible and the Mishnah. Philadelphia: Fortress, 1981.

NOGUEIRA, Paulo A. de S.; FUNARI, Pedro Paulo A.; COLLINS, John J. (Org.). Identidades fluidas no judaísmo antigo e no cristianismo primitivo. São Paulo: Annablume; FAPESP, 2010.

REED, Annette Yoshiko. Fallen angels and the history of Judaism and Christianity: the reception of Enochic literature. New York: Cambrigde University Press, 2005 .

SACCHI, Paolo. Jewish apocalyptic and its history. Sheffield: Sheffield Academic Press, 1997.

SANDERS, E. P. Judaism: practice and belief 63 BCE-66 CE. London: S. C. M. Press; Trinity Press international, 1992.

TERRA, Kenner R. C. De guardiões a demônios: a história do imaginário do pneûma akátharton e sua relação com o mito dos vigilantes. São Bernardo do Campo, 2010. Dissertação (Mestrado em Ciências da Religião) - Faculdade de Filosofia e Ciências da Religião, Universidade Metodista de São Paulo.

VANDERKAM, James C. Enoch and the growth of an apocalyptic tradition. Washington, DC: The Catholic Biblical Association of America, 1984.

VANDERKAM, James C. Enoch, a man for all generations. Columbia: University of South Carolina Press, 1995. 